\title{
Geographical Information System (GIS) as an Innovative Adoption to Ease Customers in Locating SME Business Premises in Malacca
}

\author{
Yusri bin Arshad ${ }^{1}$, Muhammad Syahir bin Mohd Sani ${ }^{2}$, Sharifah Norhafiza binti Syed Ibrahim* \\ 1,2 Faculty of Technology Management and Technopreneurship, Universiti Teknikal Malaysia Melaka, Hang Tuah Jaya, 76100 \\ Durian Tunggal, Melaka, Malaysia. \\ ${ }^{1}$ Sustainable IT Economics and Information system research group (SuITE), Centre for Technopreneurship Development (C- \\ TeD) Centre of Excellence, Universiti Teknikal Malaysia Melaka \\ * Faculty of Accountancy, Universiti Teknologi Mara, Jasin Campus, Melaka, Malaysia
}

\begin{abstract}
Geographical Information System (GIS) is one of the recent innovation to ease users in locating places. GIS is a system designed to capture, store, manipulate, analyze, manage, and present all types of spatial or geographical data. It can also be used by customers in locating business premises. Research related to application of GIS in locating SME business premises especially in Malacca as a tourist state is still very limited. This study used a survey method to produce more generalizable findings. Quantitative procedures for data collection and analysis were rigorously applied to ensure reliability and validity of the findings. A total of 160 usable responses was collected from 400 distributed questionnaires. This study found all variables significant and therefore, all hypotheses were accepted. In the future, researchers may extend this study to other areas to understand more about current usage patterns and reasons for its adoption. Studies which cover non-Malaysian respondents and different education levels can further document different perspectives of GIS adoption.
\end{abstract}

\section{Introduction}

A geographic information system (GIS) is a system designed to capture, store, manipulate, analyze, manage, and present all types of spatial or geographical data. The acronym GIS is sometimes used for geographic information science (GIScience) to refer to the academic discipline that studies geographic information systems and is a large domain within the broader academic discipline of geoinformatics. The term describes any information system that integrates, stores, edits, analyzes, shares, and displays geographic information. GIS applications are tools that allow users to create interactive queries (user-created searches), analyze spatial information, edit data in maps, and present the results of all these operations. Geographic information science is the science underlying geographic concepts, applications, and systems. One of the Global Positioning System (GPS) functional tool such as Google Map are associated with the small and medium-sized enterprises (SMEs) businesses providing satellite imagery, street maps, $360^{\circ}$ panoramic views of streets (Street View), real-time traffic conditions [1], and route planning for traveling by foot, car, bicycle in beta, or public transportation, and an API that allows maps to be embedded on third-party websites, and offers a locator for urban businesses and other organizations in numerous countries around the world that influence the easiness of customer in finding the small and medium-sized enterprises (SMEs) businesses location. The objectives of the study include:

1. To identify the benefits of using GIS software by customer to find the SME business in Malacca.

2. To determine the factor that ease the customer in adopting GIS software.

3. To examine the most significant factor in adopting GIS software.

\section{Literature Review}

\subsection{Geographical Information System}

GIS is one of many information technologies that have transformed the ways geographers conduct research and contribute to society. In the past two decades, these information technologies have had tremendous effects on research techniques specific to geography, as well as on the general ways in which scientists and scholars communicate and collaborate.

The acronym GIS is sometimes used for geographic information science (GIScience) to refer to the academic discipline that studies geographic information systems and is a large domain within the broader academic

* Corresponding author: ayusri@utem.edu.my 
discipline of geoinformatics. The term describes any information system that integrates, stores, edits, analyzes, shares, and displays geographic information. GIS applications are tools that allow users to create interactive queries (user-created searches), analyze spatial information, edit data in maps, and present the results of all these operations. Geographic information science is the science underlying geographic concepts, applications, and systems. The Global Positioning System is the responsibility of the Joint Program Office, a component of the Space and Missile Center at El Segundo, California. In 1973, the Joint Program Office was directed by the US Department of Defense to establish, develop, test, acquire, and deploy a spaceborne positioning system. The present navigation system with timing and ranging Global Positioning System (GPS) is the result of this initial directive. GPS was conceived as a ranging system from known positions of satelites in space to unknown positions on land, at sea, in air and space. Effectively, the satelite signal is continually marked with its own transmission time so that when received the signal transit period can be measured with a synchronized receiver. The original objectives of GPS were the instantaneous determination of position and velocity such as navigation, and the precise coordination of time such as time transfer (GNSS - Global Navigation Satellite Systems, 2008).

\subsection{Small and medium-sized enterprises (SMEs)}

Small and medium-sized enterprises (SMEs) businesses are largely growing nowadays in a huge amount of business being conducted. They are often described as efficient and prolific job creators, the seeds of big businesses and the fuel of national economic engines. Small and Medium Industries Development Corporation Malaysia (SMIDEC) classified small and medium-sized enterprises (SMEs) based on the yearly sales turnover or quantity of full time worker [2]. Malaysian small and medium-sized enterprises (SMEs) can be defined according to size, turnover and activity but most small and medium-sized enterprises (SMEs) businesses have a quite similar problem that is in term of providing an exact location of their business store to their target customer. Small and medium-sized enterprises (SMEs) can be divided into three sectors which are manufacturing, services and agriculture.

In the broadband economy, SMEs enjoy technologysupported opportunities to interact with customers in ways that were neither possible nor thinkable until recently. However, to effectively sustain SMEs' competitive position, technology must first meet the business needs of small enterprises. In a competitive market like the current one, knowledge and its management have become the best partner to generate competitive advantages in small and medium enterprises. It is important for country economic development that SMEs, as main source of wealth, manage their intangible resources to continue creating value, both business and social, and get to be leader in an international and competitive market, in order to gain advantages to present difficult situation due to financial crisis [3]

\subsection{Theoretical Framework}

Using the GIS software to relay the location information is all well and good, but how best to impart the relationship reasoning behind it is explained in theoretical framework. A theoretical framework is a type of intermediate concept which has the ability to connect all aspects of inquiries. A framework can help decide and explain the route that should be taken to a certain point [4, 5]. The study framework comprises the dependent variable (Social Influence, Time Management, Effort Expectancy, Performance Expectancy, and Facilitating Condition) and the independent variable (Behavioral Intention to adopt GIS software). Experience acts as the moderator variable.

\subsection{Factors Affecting the Adoption of Geographical Information System}

From literature, GIS adoption factors can include Social Influence, Time Management, Effort Expectancy, Performance Expectancy, and Facilitating Condition.

\subsubsection{Social Influence}

Social influence occurs when a person's emotions, opinions, or behaviors are affected by others. Social influence takes many forms and can be seen in conformity, socialization, peer pressure, obedience, leadership, persuasion, sales, and marketing. Social influence is defined as the degree to which a person perceives that important others believe he or she should use the GIS. A study conducted by [6] found the most significant positive impact was of social influence on consumer's intention to adopt mobile banking services in Pakistan. Hence, this study proposed hypothesis $\rightarrow \mathrm{H} 1$ : There is positive and significant relationship between social influence and behavioral intention to adopt GIS software.

\subsubsection{Time Management}

Time management in any organization and in life generally is of essence if the objective of existence of such entity is to be realized. The quest for better and more efficient way of doing things, continuous pursuit of efficiency, increased productivity initially in manufacturing but later expanded to focusing on individual efficiency in offices brought about the study of managing the time at everyone's disposal. Lawson et. al, [7] mentioned that the findings from the existing literature addressing GIS, GPS are limited at this time and the primary issue of GPS as a source of travel data relates to the satellite signal that improve the time taken and advancements in the technology being used for the GPS units appear to offer possible solutions to some of the issues regarding urban canyon effect, tree canopies, and other physical obstructions. The time management of GIS is a major help for the customer on the easiness for them to locate the SMEs premises location. 
The efficient management of time is one of the most important aspects of project management; frequently it is the most critical aspect for a client. Time itself is unmanageable, and, if it is critical, must be treated as a diminishing resource from day one. Since time as a resource cannot be increased, it follows that time management really relates to the management of the activities involving any other resource within an allocated period. The effluxion of time is continuous, very easily passing unnoticed, especially in the early stages of a project; and unless a positive attitude to its use is taken from the outset, the project can very quickly be in trouble [14]. Hence, hypothesis two is $\rightarrow \mathrm{H} 2$ : There is positive and significant relationship between time management and behavioural intention to adopt GIS software.

\subsubsection{Effort Expectancy}

Perceived ease-of-use (PEOU) was defined by Davis (1989) as "the degree to which a person believes that using a particular system would be free from effort". Expectancy theory is based on four assumptions [9]. One assumption is that people join organizations with expectations about their needs, motivations, and past experiences. These influence how individuals react to the organization. A second assumption is that an individual's behavior is a result of conscious choice. That is, people are free to choose those behaviors suggested by their own expectancy calculations. A third assumption is that people want different things from the organization (e.g., good salary, job security, advancement, and challenge). A fourth assumption is that people will choose among alternatives so as to optimize outcomes for them personally $[2,13]$. Therefore, the study proposed hypothesis three as $\rightarrow \mathrm{H} 3$ : There is positive and significant relationship between effort expectancy and behavioral intention to adopt GIS software.

\subsubsection{Facilitating Condition}

Merriam-Webster defines Awareness as the knowing that something such as a situation, condition, or problem exists, and feeling, experiencing, or noticing something such as a sound, sensation, or emotion knowing and understanding a lot about what is happening in the world or around you. Awareness is the ability to perceive, to feel, or to be conscious of events, objects, thoughts, emotions, or sensory patterns. In this level of consciousness, sense data can be confirmed by an observer without necessarily implying understanding. More broadly, it is the state or quality of being aware of something. In biological psychology, awareness is defined as a human's or an animal's perception and cognitive reaction to a condition or event. Based on the study conducted by [2,10], effort expectancy is major predictor technology adoption. Many studies incorporated a few variables such as Performance expectancy, effort expectancy, and subjective norm as facilitating conditions to adopt technologies. Thus, hypothesis four is $\rightarrow \mathrm{H} 4$ : There is positive and significant relationship between facilitating condition and behavioral intention to adopt GIS software.

\subsubsection{Performance Expectancy}

Investopedia defines efficiency signifies a level of performance that describes a process that uses the lowest amount of inputs to create the greatest amount of outputs. Efficiency relates to the use of all inputs in producing any given output, including personal time and energy. Efficiency is a measurable concept that can be determined by determining the ratio of useful output to total input. It minimizes the waste of resources such as physical materials, energy and time, while successfully achieving the desired output. Efficiency is often measured as the ratio of useful output to total input, which can be expressed with the mathematical formula $\mathrm{r}=\mathrm{P} / \mathrm{C}$, where $\mathrm{P}$ is the amount of useful output ("product") produced per the amount C ("cost") of resources consumed. Hence, hypothesis five is $\rightarrow \mathrm{H} 5$ : There is a positive and significant relationship between performance expectancy and behavioral intention to adopt GIS software.

\subsubsection{Experience}

This study is also interested in evaluating experience as a moderator for GIS adoption. Ramayah et al., [8] study prior experience as moderating variable among students. They found that prior experience helped in solving easier problems only and not harder tasks. Moderating variable function is to test the relationship between independent and dependent variable which is not only surprisingly weak but also inconsistent or non-existence. Thus, the moderating variable is included to reduce or strengthen the relationship.

H1a: The influence of social influence factor on individual intention will be moderated by experience.

H2a: The influence of time management factor on individual intention will be moderated by experience. H3a: The influence of effort expectancy factor on individual intention will be moderated by experience. H4a: The influence of performance expectancy factor on individual intention will be moderated by experience. H5a: The influence of facilitating condition factor on individual intention will be moderated by experience. 


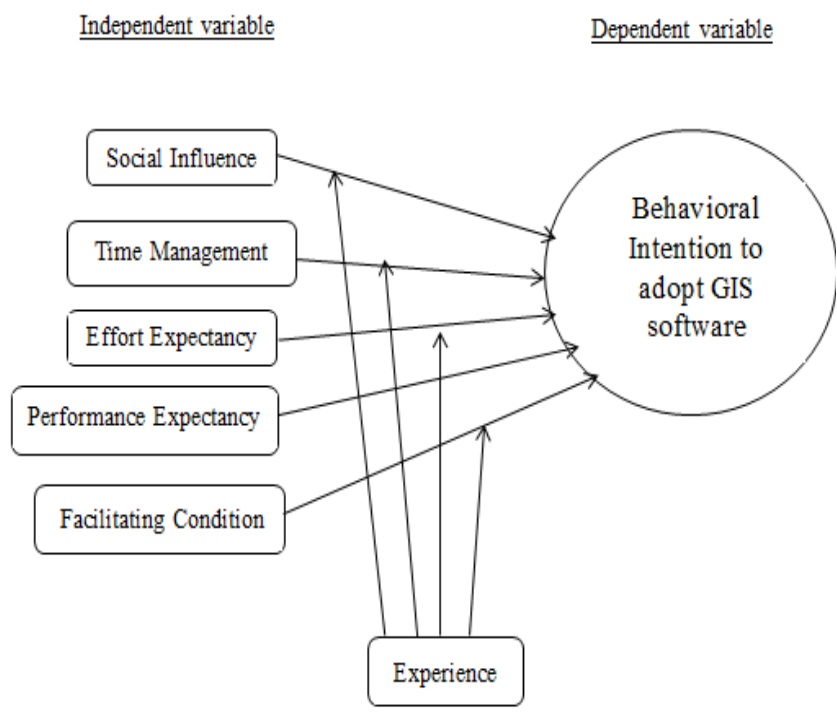

Fig. 1. Research model

\section{Methodology}

This research employs quantitative survey method. Quantitative method is best at assessing relationship between factors and to test regressions at advanced level [4]. The study managed to get 160 responses or $40 \%$ from total 400 surveys distributed to customers on SME premises around Jalan Hang Tuah, Melaka. These 160 respondents were selected randomly. The questionnaire was divided into two parts that are Section A for Demographic Profile and Section B for Variables. A 5point Likert scale rating was used to assess end user acceptance of a software program. Pre-test was done to get input from experts on the design of the questionnaire. Ten pre-tests feedback was received. A small improvement was made before pilot study was undertaken. From the 160 responses, the researchers used statistic package for the social science (SPSS) to analyse the results. Cronbach Alpha reliability and internal validity checks were carried out [5].

\section{Results}

\subsection{Descriptive Analysis}

Pilot test analysis involved 28 responses. Cronbach's alpha for this pilot was 0.824 , which is high and accepted as very good level. This section explain the demographic information of respondents including gender, race, GIS usage frequency. The respondents constituted $80 \%$ malays and $10 \%$ each for indian and chinese. Female dominated as repondents which is around $70 \%$ as shown in Table 1 and 2 respectively.

Table 1. Gender of respondents
GENDER

\begin{tabular}{|ll|r|r|r|r|}
\hline & & Frequency & Percent & Valid Percent & $\begin{array}{c}\text { Cumulative } \\
\text { Percent }\end{array}$ \\
\hline Valid & MALE & 48 & 30.0 & 30.0 & 30.0 \\
& FEMALE & 112 & 70.0 & 70.0 & 100.0 \\
& Total & 160 & 100.0 & 100.0 & \\
\hline
\end{tabular}

Table 2. Frequencies for using GIS applications

\begin{tabular}{|c|c|c|c|c|c|}
\hline & 0 & Frequency & Percent & Valid Percent & $\begin{array}{c}\text { Cumulative } \\
\text { Percent }\end{array}$ \\
\hline \multirow[t]{5}{*}{ Valid } & Never & 40 & 25.0 & 25.0 & 25.0 \\
\hline & Once a week & 100 & 62.5 & 62.5 & 87.5 \\
\hline & 2 to 4 times a week & 10 & 6.3 & 6.3 & 93.8 \\
\hline & 5 or more times a week & 10 & 6.3 & 6.3 & 100.0 \\
\hline & Total & 160 & 100.0 & 100.0 & \\
\hline
\end{tabular}

In Table 2, only $6.3 \%$ respondents said that they were frequent users of GIS applications to locate SME premises. $6.3 \%$ also said they used 2 to 4 times a week whereas a vast majority of $62.5 \%$ claimed that the used only once a week. $25 \%$ said the have never used GIS applications to locate SME premises.

\subsection{Correlation Analysis}

A correlation coefficient enables us to quantify the strength of the linear relationship between two ranked or numerical values [5].

Table 3. Correlation analysis

Correlations

\begin{tabular}{|c|c|c|c|c|c|c|c|}
\hline & & $\begin{array}{l}\text { Performance } \\
\text { Expectancy } \\
\end{array}$ & $\begin{array}{c}\text { Social } \\
\text { Influence }\end{array}$ & $\begin{array}{c}\text { Effort } \\
\text { Expectancy }\end{array}$ & $\begin{array}{r}\text { Facilitating } \\
\text { Condifion }\end{array}$ & $\begin{array}{c}\text { Time } \\
\text { Management }\end{array}$ & $\begin{array}{l}\text { Behavioral } \\
\text { Intention }\end{array}$ \\
\hline \multirow[t]{3}{*}{ Performance Expectancy } & Pearson Cortelation & 1 & .462 & .371 & .441 & $.667^{\prime \prime}$ & .528 \\
\hline & Sig. (2-tailed) & & .072 & .158 & .088 & .005 & .035 \\
\hline & N & 16 & 16 & 16 & 16 & 16 & 16 \\
\hline \multirow[t]{3}{*}{ Social Infuence } & Pearson Conrelation & 462 & 1 & .163 & .192 & .182 & $500^{\circ}$ \\
\hline & Sig. (2tailed) & .072 & & .547 & .475 & .501 & .049 \\
\hline & N & 16 & 16 & 16 & 16 & 16 & 16 \\
\hline \multirow[t]{3}{*}{ Effort Expectancy } & Pearson Contelation & .371 & .163 & 1 & .388 & .445 & $.560^{\circ}$ \\
\hline & Sig. (2.tailed) & 158 & .547 & & .137 & .084 & .024 \\
\hline & N & 16 & 16 & 16 & 16 & 16 & 16 \\
\hline \multirow[t]{3}{*}{ Faclitating Condation } & Pearson Conrelation & .441 & .192 & .398 & 1 & $.785^{\prime \prime}$ & $.752^{\prime \prime}$ \\
\hline & Sig. (2-tailed) & .088 & .475 & .137 & & .000 & .001 \\
\hline & N & 16 & 16 & 16 & 16 & 16 & 16 \\
\hline \multirow[t]{3}{*}{ Time Management } & Pearson Correlation & .667 & .182 & .445 & $.785^{\prime \prime}$ & 1 & .502 \\
\hline & Sig. (2.tailed) & .005 & .501 & .084 & .000 & & .047 \\
\hline & N & 16 & 16 & 16 & 16 & 16 & 16 \\
\hline \multirow[t]{3}{*}{ Behavioral Intention } & Pearson Conrelation & $.528^{\prime}$ & $500^{\circ}$ & $.560^{\circ}$ & $.752^{\prime \prime}$ & $.502^{\prime}$ & 1 \\
\hline & Sig. (2-tailed) & 035 & .049 & .024 & .001 & .047 & \\
\hline & $\mathrm{N}$ & 16 & 16 & 16 & 16 & 16 & 16 \\
\hline
\end{tabular}

". Correlation is significant at the 0.01 level (2.tailed).

$\therefore$ Correlation is significant at the 0.05 level (2-tailed).

In Table 3 above, all variables show high correlations and $\mathrm{p}$ values. For example, the correlation between the Performance Expectancy and Behavioral Intention is $0.528(\mathrm{p}=0.035)$. This correlation coefficient is therefore a statistically significant. Secondly, the correlation between the Social Influence and Behavioral Intention is 
$0.500(\mathrm{p}=0.049)$. Thirdly, the correlation between the Effort Expectancy and Behavioral Intention is 0.560 $(p=0.024)$. Fourthly, the correlation between the Facilitating Condition and Behavioral Intention is 0.752 $(p=0.001)$. Finally, the correlation between the Time Management and Behavioral Intention is $0.502(\mathrm{p}=0.047)$.

\subsection{Hypothesis Testing}

There is a significant relationship between independent variable and dependent variable if the significant value was below $0.05(p<0.05)$. The multiple correlation coefficients were the linear correlation between the observed and the model predicted values of dependent variable.

Based on Table 4 below, all variables show high $\mathrm{p}$ values and therefore, all hypotheses were accepted.

Table 4. Hypothesis testing

\begin{tabular}{|c|c|c|}
\hline Item & Findings & Relationship \\
\hline $\begin{array}{c}\text { Hypothesis } \\
1\end{array}$ & $\begin{array}{c}\text { Accepted } \\
\mathrm{p} \text { value }=0.035\end{array}$ & $\begin{array}{l}\text { Moderate positive relationship } \\
\qquad \mathrm{r}=0.528\end{array}$ \\
\hline $\begin{array}{c}\text { Hypothesis } \\
2\end{array}$ & $\begin{array}{c}\text { Accepted } \\
\mathrm{P} \text { value }=0.049\end{array}$ & $\begin{array}{l}\text { Moderate positive relationship } \\
\qquad \mathrm{r}=0.500\end{array}$ \\
\hline $\begin{array}{c}\text { Hypothesis } \\
3\end{array}$ & $\begin{array}{c}\text { Accepted } \\
\mathrm{P} \text { value }=0.024\end{array}$ & $\begin{array}{l}\text { Moderate positive relationship } \\
\qquad \mathrm{r}=0.560\end{array}$ \\
\hline $\begin{array}{c}\text { Hypothesis } \\
4\end{array}$ & $\begin{array}{c}\text { Accepted } \\
\mathrm{P} \text { value }=0.001\end{array}$ & $\begin{array}{l}\text { High positive relationship } \\
\qquad \mathrm{r}=0.752\end{array}$ \\
\hline $\begin{array}{l}\text { Hypothesis } \\
5\end{array}$ & $\begin{array}{c}\text { Accepted } \\
\mathrm{P} \text { value }=0.047\end{array}$ & $\begin{array}{l}\text { Moderate positive relationship } \\
\qquad \mathrm{r}=0.502\end{array}$ \\
\hline
\end{tabular}

\section{Discussion}

Geographically referenced data consist of any type of measurement or observation, whether analog or digital, which have a known distribution across the surface of the ground, and hence can be presented as a map. Computer software programs designed to store, manipulate and present geographical data are known as geographical information systems (GIS) [11].

GIS applications are tools that allow users to create interactive queries (user-created searches), analyze spatial information, edit data in maps, and present the results of all these operations. Geographic information science is the science underlying geographic concepts, applications, and systems. One of the Global Positioning System (GPS) functional tool such as Google Map is associated with the small and medium-sized enterprises (SMEs) businesses providing satellite imagery, street maps, $360^{\circ}$ panoramic views of streets (Street View), real-time traffic conditions (Google Traffic), and route planning for traveling by foot, car, bicycle in beta, or public transportation, and an API that allows maps to be embedded on third-party websites, and offers a locator for urban businesses and other organizations in numerous countries around the world that it can search by keyword such as type of business that influence the easiness of customer in finding the small and medium-sized enterprises (SMEs) businesses location [1].

The benefits of using GIS software has also been support by Bing Pan, John C. Crotts, and Brian Muller in their book 'Information and Communication Technologies in Tourism 2007' that saying the handheld tour guide is based on mobile phones with a GPS antenna to communicate with Google Map and deliver real-time and location-sensitive tourist information. Online Charleston trip planner combines destination specific information with Google Map to provide an interactive trip planning tool based on the map metaphor. The handheld tour guide is slow and unstable due to memory limitations and slow Internet connection provided by the mobile phone service. The online trip planner is being adopted by various hotels and conferences. The development effort demonstrated that Google Map API is a flexible tool with reasonable speed for developing destination-specific online services. For mobile tools, the computing power and wireless connections of small devices are the bottlenecks when communicating with online services [12].

Objective 2 is to determine the factors that ease customers in adopting GIS software. Literature mentioned many factors used frequently by past researchers. However, Technology acceptance model (TAM) and UTAUT models 1 and 2 suggests several tested and confirmed acceptance and adoption factors. Hence, the researchers gathered six independent variables that have been used to identify its impact towards behavioral intention. As shown in Figure 1, the theoretical framework was developed to identify the impact of social influence, time management, effort expectancy, performance expectancy, and facilitating condition on behavioral intention.

From the research, it has been found that social influence, effort expectancy, performance expectancy, and facilitating condition factors were adopted from UTAUT model. The theory holds that there are four key constructs: 1) performance expectancy, 2) effort expectancy, 3) social influence, and 4) facilitating conditions. The first three are direct determinants of usage intention and behavior, and the fourth is a direct determinant of use behavior.

Other than that, based from the hypothesis there is a positive and significant relationship between the independent variable of social influence, time management, effort expectancy, performance expectancy, and facilitating condition to the dependent variable of behavioral intention to adopt GIS software by having the ' $p$ ' value to be lower than 0.05 . This means that the independent variables are significant enough to be considered as the factor in adopting GIS software.

Objective 3 is to examine the most significant factors in adopting GIS software. The regression analysis was done to develop a model of adoption using the behavioral 
intention as an element. The result of behavioral intention (dependent variable) against all the independent variables can be seen in the table above which $p<0.05$. In this research, the $p$ value is less than 0.05 thus the model of regression is a significant.

The outcome can be examined from the linear regression that is the Facilitating Condition as the most affecting factor in adopting GIS software because it has the highest significant level and also by increasing $1 \%$ of Facilitating Condition will increase the Behavioral Intention for $1.093 \%$ and followed by time management as the second highest significant level, and then effort expectancy and experience as the third highest significant level.

\section{Conclusion}

This research is to study the adoption of Geographical Information System (GIS) to ease customers in locating SME business premises along Jalan Hang Tuah Malacca. Based on previous discussion, this study concludes that the related factors directly impact one another and consequently they influence user's behavioral intention to adopt GIS software. Almost $70 \%$ of the respondents were in the category of never use GIS or use GIS less than once a week. Further studies are necessary to understand why there is a slow growth in using GIS for locating business premises or even tourist places. Examples of mostly used GIS or GPS applications are google maps and waze applications to assist in road traveling.

UTAUT and TAM are two theories researchers most referred to in technology adoption and acceptance studies. Based on these models and other related literature, this study developed and tested six variables and it found all variables were significant influencers in the study. Hence, all hypotheses were accepted. It is interesting to note that Facilitating Condition is the most significant factor in adopting GIS software because it has the highest significant level and also by increasing $1 \%$ of Facilitating Condition will increase the Behavioural Intention by $1.093 \%$. The next factors ranked by their significant level were time management, effort expectancy and experience.

In the future, researchers may extend this study to other areas to understand more about current usage patterns and reasons for its adoption. Studies which cover nonMalaysian respondents and different education levels can further document different perspectives of GIS adoption.

The authors would like thank to Universiti Teknikal Malaysia Melaka for sponsoring this publication. We would also like to thank Ministry of Higher Education, Sustainable IT Economics research group, Faculty of Technology Management and Technopreneurship (FPTT) and respondents who helped us along the way to completion of this research..

\section{References}

1. Wikipedia (2017). Retrieved from https://en.wikipedia.org/wiki/Google_Maps

2. Moorthy, M.K., Tan, A., Choo, C., Wei, C.S., Tan, J., Ping, Y., \& Leong, T.K. (2012). A Study on Factors Affecting the Performance of SMEs in Malaysia. Academic Research in Business and Social Sciences, 2(4), 224-239.

3. I. Alvarez, E. Cilleruelo, I. Zamanillo \& E. Zarrabeitia (2014) Knowledge Management Practices in SME: Case Study in Basque Country SME, Annals of Industrial Engineering 2012

4. Y. Arshad. (2012). IT Outsourcing Decisions and Implementations In Malaysian Public Healthcare Sector Agencies: Grounding An ITO Relationship Model Using Qualitative Approach. Unpublished thesis. International Islamic University Malaysia.

5. A. R. Ahlan, M. A. Suhaimi, H. Hussin, Y. Arshad (2008). Assessing future needs of IT Education in Malaysia: A preliminary result. Proceedings of 4th WSEAS/IASME International Conference on educational Technology (EDUTE'08), Corfu, Greece

6. J. M. Burger (1992). Social Influence, Desire for Control, Part of the series The Plenum Series in Social / Clinical Psychology pp 63-79

7. C. T. Lawson et al. (2007) GPS Pilot Project Phase One: Literature And Product Review

8. T. Ramayah, I. Joshua and A. Bushra (2005) Personal computer Usage Among Students In A Private Institution of Higher Learning: The Moderating Role Of Prior Experience. The Asia Pacific Journal of Educators and Education (formerly known as Journal of Educators and Education), 20 (1). pp. 1-22. ISSN 2289-9057

9. V. H. Vroom. (1964) Work and motivation. New York: Wiley.

10. F. C. Lunenburg (2011). Expectancy Theory of Motivation: Motivating by Altering Expectations

11. R. W. Marjoribanks (1997). Geographical Information Systems, Geological Methods in Mineral Exploration and Mining

12. B. Pan, J. C. Crotts, B. Muller (2007). Developing Web-Based Tourist Information Tools Using Google Map, Information and Communication Technologies in Tourism 2007

13. M. Renko, K. G. Kroeck \& A. Bullough (2012). Expectancy theory and nascent entrepreneurship, Small Business Economics

14. T. Gudehus \& H. Kotzab (2012). Time Management, Comprehensive Logistics. 